\section{Funding Opportunities for Ac- quiring Major Equipment from Federal Granting Agencies} M\&M 2004 Core Facility Management - Part I: NIH

\author{
Organizer: Debby Sherman, Purdue University \\ (dsherman@purdue.edu)
}

D. Sherman: The session this year will be on the topic of "How to get funds for major equipment via programs through the two major granting agencies, NIH and NSF, that fund major equipment acquisition.

I would now like to introduce our first speaker Dr. Marjorie Tingle who is representing the NIH. Marjorie is a health sciences administrator for the National Center for Research Resources at NIH. This is a very important agency in that it provides funding for primarily biomedical researchers for diverse instrumentation, technologies, basic clinical research facilities, animal models, and more. Dr. Tingle has planned, directed, and administered several major grant programs including Institutional Development Awards, Science Education and Minority programs. At the present time, she is the director of the NCRR Shared Instrumentation and a High-End Instrumentation programs. With the cost of major instrumentation these days, I expect there will be a significant increase in the applications for these very high-end instrumentation grants. These programs provide funds for requests of $\$ 100,000$ and on up into the millions.

\section{Dr. Marjorie Tingle:}

Thank you to the society for inviting me here today. I do not know how many of you are familiar with the NIH grant process so I would like to show some general NIH websites for funding opportunities. The home page is http://grants1.nih.gov/grants/. NIH is composed of 28 institutes and centers. Most of these are categorical. Their mission is to support research on the prevention or treatment of different diseases such as the National Eye Institute or the National Cancer Institute. There are other institutes or centers that support basic biomedical research such as the National Institute for General Medical Sciences and the National Human Genome Research Institute, the new National Institute of Biomedical Imaging and Bioengineering, and the National Center for Research Resources.

All the Institutes can issue requests for applications (RFA's) or Program Announcements (PA's) to generate interest in specific research areas. All of these funding opportunities are published weekly in the NIH Guide to Grants and Contracts, which can be found on the Office of Extramural Research (OER) homepage http://grants1. nih.gov/grants/oer.htm. You can browse the NIH Guide to see what the current announcements are or you can search in the archives for specific announcements. There are also unsolicited applications such as regular investigator-initiated research project grants and training grants which have receipt dates three times a year. I do want to point out a new section on the NIH commons. This website (https://commons.era.nih.gov/commons/) is a personal website for all NIH applicants. It allows you to go in and check the current status of your grant applications. Status information would include when it was received, when it is going to be reviewed, who is going to be the person in charge of the review. When the review is over the score will be on your website within 2-3 days and 4-5 weeks later the summary statement, a critique of the review, will be available on that website. You must go to your sponsored programs office and get a password to register for the $\mathrm{NIH}$ Commons. I really urge you to do this because in the future most of your transactions will be through that website.
Another aspect of NIH is that the program and review functions are separate. We have a separate entity at NIH called the Center for Scientific Review (CSR). That is where your application first goes when it is received at NIH. The receipt and referral office, gives the application a grant number and then it is assigned to a specific institute for funding and to a study session for review. Information about the peer review process is available on the CSR website. The referral office in CSR is where your point of contact if, for example, you need an extension of a deadline for your application or after you have submitted an application you realize that you left out a few pages, a CV or other information.

On the programmatic side, the National Center for Research Resources supports access to research models, technologies, clinical centers, etc. It is non-categorical in nature in that the mission of NCRR is to provide infrastructure support for NIH research grantees. The Biomedical Technology section of NCRR funds regular investigator-initiated research projects as well as high-risk pilot projects for the development of new technologies, new instrumentation, and new software. NCCR also sponsors Small Business Innovative Research programs. Funding opportunities can be found at http://www.ncrr.nih.gov/.

The two major instrumentation programs administered by the NCRR are the Shared Instrumentation Grant Program (SIG) and High-End Instrumentation Programs (HEI). For the Shared Instrumentation Program, the minimum cost for a single instrument is $\$ 100,000$. The maximum award is capped at $\$ 500,000$. In the High-End Program the minimum cost of a single instrument is $\$ 750,000$ and the upper limit on the award is 2 million dollars. Obviously, all these instruments in these cost ranges are too expensive to be funded on a regular research grant.

Funded instruments are usually placed in core facilities and shared by a large group of NIH investigators. If you go to the NCRR website for either of these programs you will get clear description of the features of both programs. You can also access the latest program announcements and all the grants awarded for the last 10 years. The latter is very important site for information. From the list you contact someone from your institution that has submitted a successful grant and use his or her application as a model.

Some of the features of the SIG program are:

1. Provides capital costs for the acquisition of new instruments or the purchase of up-dated instruments. Development is separate from acquisition.

2. Provides direct costs only (no maintenance, supplies or technical support).

3. There is one receipt date per year.

4. The awards are for 1 year only.

5. There is no restriction on the number of applications an institution can send in per year.

The minimal requirement for the program is a group of NIH investigators that have a need for the instrumentation. A successful application is one that has demonstrated need for the instrumentation, has shown that it can enhance NIH-funded research, demonstrates appropriate technical expertise, offers a good plan to administer the grant, and has reasonable institutional commitment.

New instrumentation needs have increased greatly in the last two years. The number of applications to the Shared Instrumentation program has actually increased by $30 \%$. The largest class of instruments by far is the confocal, deconvolution, and multi-photon microscope group that makes up almost 25 percent of the applications. Of the $\$ 166$ million dollars requested, a quarter of that is for these microscopes excluding electron microscopes. 


\section{STOP HASSLING WITH}

MULTIPLE SERVICE CONTRACTS!

START by putting all of your instruments under one service contract with MAS (regardless of make or model). Our expert EM SERVICE GROUP has the knowledge and skills to keep your instrument working at its best.

\section{TEM'S/SEM'S PREP EQUIPMENT SPECIAL SERVICES}

\section{HITACHI TOPCON JEOL ISI \\ AMRAY CAMBRIDGE}

\section{VACUUM COATERS \\ STAGES}

PLASMA ASHERS

SPUTTER COATERS

ION MILLS
BEAM BLANKERS

CUSTOM DEVICES

\section{NEW NEW NEW}

Authorized service representatives for Gatan preparation equipment and Topcon TEM'S.
Contracts and On-Demand

Emergency Service at

Reasonable Rates from

Factory Trained Specialists.

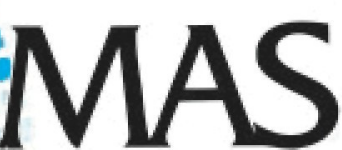

\section{0-421-8451}

3945 Lakefield Crent Suwaned, Georgia 30024 770-866-3200 FAX 770-866-3254 616 Hutton Sirest Suite IOI Raleigh, Noth Ganlina 27606 919-829-704I FAX919-829-5518 ADNANCED ANALYTICAL PRODUCTS AND SERVICES

\section{HITACHI S4500 FESEM FOR SALE}

Options include: 5 axis motorized Deben stage, large chamber and airlock, GW chamber scope, magnetic levitation turbo pump and clean vacuum system. This scope was always maintained under service contract. Price $\$ 150 \mathrm{~K}$ with installation and $1 \mathrm{yr}$. warranty service (USA only). All inquiries considered. Contact M.W. Rigler, Ph.D. at 800-421-8451 or email mrigler@mastest.com.

\section{Addendum}

In the article "Automated Functions in Electron Microscopy" by Bill Tivol (Microscopy Today, November 2004, pp 14-18), the author wishes to add this figure to the article's appendix.
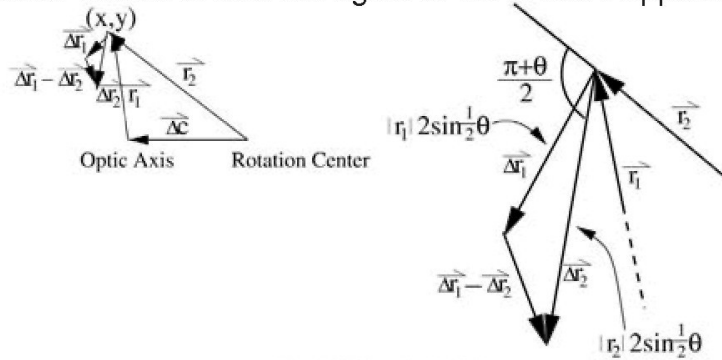

$\forall(x, y) \in \mathrm{I}, \quad \overrightarrow{\Delta \mathrm{r}_{1}}=2 \sin \frac{1}{2} \theta\left(\begin{array}{cc}\cos \left(\frac{\pi+\theta}{2}\right) & \sin \left(\frac{\pi+\theta}{2}\right) \\ -\operatorname{sir}\left(\frac{\pi+\theta}{2}\right) & \cos \left(\frac{\pi+\theta}{2}\right)\end{array}\right) \vec{r}_{1}$, and

$$
\overrightarrow{\Delta \mathrm{r}_{2}}=2 \sin \frac{1}{2} \theta\left(\begin{array}{cc}
\cos \left(\frac{\pi+\theta}{2}\right) & \sin \left(\frac{\pi+\theta}{2}\right) \\
-\sin \left(\frac{\pi+\theta}{2}\right) & \cos \left(\frac{\pi+\theta}{2}\right)
\end{array}\right) \overrightarrow{\mathrm{r}_{2}} \text {. }
$$

But, $\overrightarrow{\Delta \mathrm{c}}+\overrightarrow{\mathrm{r}_{1}}=\overrightarrow{\mathrm{r}_{2}}$, and $\left(\begin{array}{cc}\cos \left(\frac{\pi+\theta}{2}\right) & \sin \left(\frac{\pi+\theta}{2}\right) \\ -\sin \left(\frac{\pi+\theta}{2}\right) & \cos \left(\frac{\pi+\theta}{2}\right)\end{array}\right)=\widehat{\mathrm{R}}\left(\frac{\pi+\theta}{2}\right)$; thus,

$\vec{\tau}=\overrightarrow{\Delta r_{2}}-\overrightarrow{\Delta r_{1}}=2 \sin \frac{1}{2} \theta \widehat{R}\left(\frac{\pi+\theta}{2}\right)\left(\overrightarrow{r_{2}}-\overrightarrow{r_{1}}\right)=2 \sin \frac{1}{2} \theta \widehat{R}\left(\frac{\pi+\theta}{2}\right) \overrightarrow{\Delta c}$,

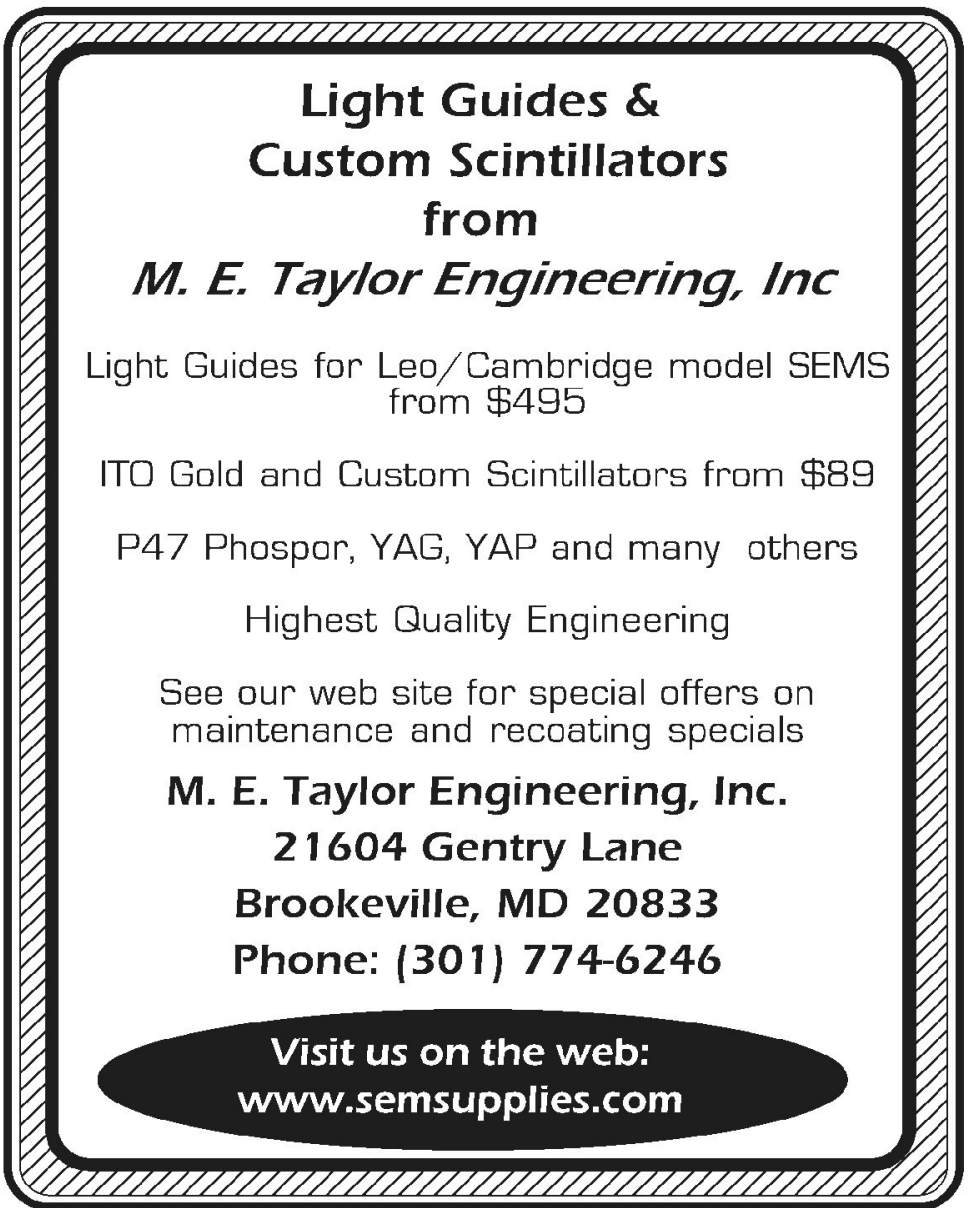


When SIG applications are received in CSR in March they are sorted into groups by instrument type and then they are reviewed by instrument-specific ad hoc study sections.

The reviewers are not going to re-review the science. The science has already been peer-reviewed when each individual investigator applied for their research grant. That makes it very difficult to write these applications. The applications are reviewed and receive a priority score from 100 (best) to 500 (worst). Since the average priority score can vary by as much as 50 points between the various study sections we do not pay to a specific priority score in the SIG Program. Instead, all the applications in each study section are percentile ranked and we pay to a specific percentile. In FY2004 we paid to the $37^{\text {th }}$ percentile.

If you don't succeed, try again. Applicants who resubmit their application have a $66 \%$ chance of being funded. The success rate for a second resubmission is also high. The reason for this is that the reviewers really take great pains during the review to help applicants and to point out the weaknesses in the application. Smart applicants really pay attention to the critique and when they resubmit they address each specific criticism item by item in the revised application. When they do that, they usually double their chance for funding.

The High-End Program has similar guidelines and allowable costs to the SIG program. The major change is the cost range and, as you would expect, we get requests for much more expensive instruments such as high-end NMRs, high-end cryo EMs, and super-computers. The receipt date for this program is September. The budget for this program is significantly smaller than the SIG program so it is a much more competitive program.

\section{Steps in submitting a successful proposal:}

1. Read Program Announcement: Applicants who fare poorly in the review usually have not paid much attention to the program announcement. Reading the program announcement is very important.

2. Choose appropriate equipment: The first thing you have to do when you write an application is to choose the appropriate instrument. You have to match the capabilities of the instrument with the needs of your user group. You have to look at the products advertised by the different vendors. You cannot rely on the instrument functioning as it says in the brochure. You have to go out and demo the instruments with your own samples. You can then make a good case for the instrument selected. If you ask for a very sophisticated instrument when all you need is a regular general-purpose piece of equipment the reviewers will think you are being greedy and will lower their score. When you decide on the instrument you will need to provide a detailed quote with a justification for any accessories requested. It will take almost a year before you get an award, so if the technology changes you can go back and reevaluate your choice.

3. Inventory existing equipment: The second thing to do is to take an inventory of similar equipment that is at your institution or nearby right now. You are probably better off to make a table listing each instrument, how old it is, and what shape it's in. You definitely need to get a letter stating that the instruments are not available for your use. This lack of accessibility need to be documented.

4. Document anticipated use: The next thing you have to do is document the current use of the instrument you have now and estimate your expected future use of the requested instrument. You have to show, for example, that the instrument will be used at least $75 \%$ of the time for NIH research. By far the biggest problem area in this whole application process is the enhancement of the research projects section. Most of the problems arise when the major users do not present a clear description of how they would use the requested instrument. They have to show that the capabilities of the instrument they requested are actually needed for their research. They have to tie in their research with the instrument. They can't just take the abstract from their regular research grant and cut and paste it into the application with a final sentence saying that the new instrument will help them tremendously. This just won't fly! You have to be able to explain what type of results you expect from this instrument, and how the results are going to enhance your present research project. The best way to do that is with preliminary data to show that you can actually get results that are useful, logical, and interpretable. You need to get some images with your existing instrument and show what the current limitations are. Then you can demo the requested instrument and produce images to show what the new instrument can do. Another pitfall is that people do not show the need for extra capabilities. For example, if you are proposing FRET, live cell or other complex imaging experiments, you will need to show data to show that you can actually get good FRET images. You also have to have some level of expertise commensurate with the additional capabilities. In this particular program when the reviewers sit down to review all those confocal applications, the first thing they do is look for images. If an application has no images in it, it is a lost cause.

5. Technical expertise: The next issue is technical expertise. You really have to have someone who knows how to run and operate the instrument. There has to be someone to train people to use the instrument and make sure the instrument is maintained properly. That is a very important criterion.

6. Administrative plan: You need to have a good administrative plan. To do this you need to establish an advisory committee. The advisory committee should have major users on it, but should also have people who do not have any vested interest in the instrument so that if a conflict arises there is someone who can resolve it. The advisory committee should also develop guidelines for use of the instrument and fee structures to pay for maintenance, supplies, etc.

7. Institutional commitment: Institutional commitment is another important criterion. Nothing sets reviewers off into gales of laughter better than a wishy washy letter from Dean saying how wonderful it would be if his or her institution could be awarded the instrument. They are rah rah cheerleader type letters which offer nothing but moral support rather than specific financial support. The letters need to have a specific dollar commitment from the institution for paying for a service contract or providing technical support or even for providing support for user fees if grant support decreases. What is often overlooked is that many institutions have a long history of adequately supporting core facilities which can be pointed to as examples of institutional commitment.

8. Benefit to the overall community: Benefit to the community is just as it says. $75 \%$ of the use should be for the NIH researchers. You should have some plan to attract other users for the other $25 \%$ of the time. You might have workshops or special training programs to bring in new users. Please note that, in contrast to NSF applications, the NIH application has no specific requirement for an educational component but you do have to have a plan to train users. This is the section where you will need to show what impact the instrument will have on biomedical research at your institution.

I hope some of these pointers will help you in preparing a real competitive and successful application. 

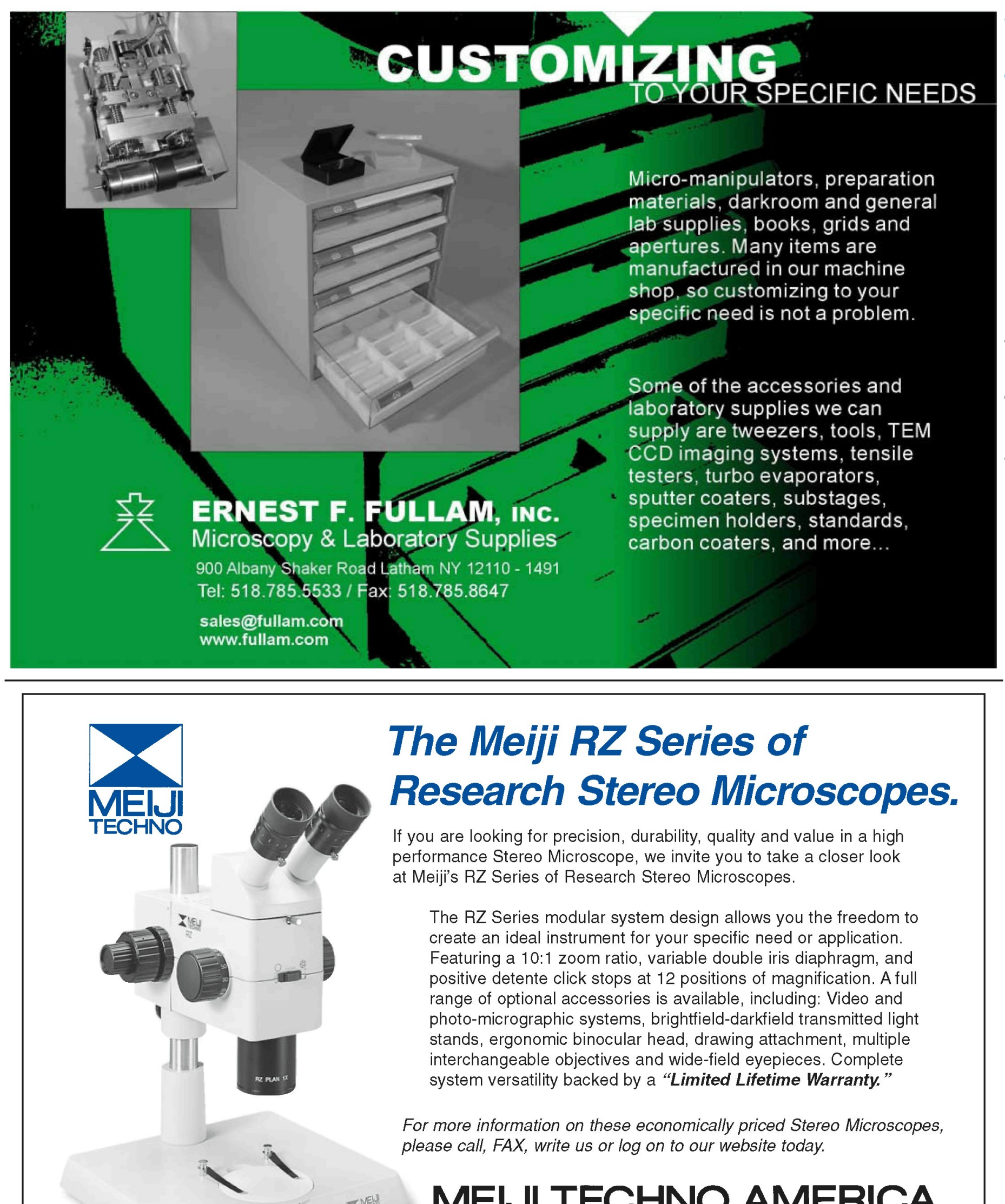

\section{The Meiji RZ Series of Research Stereo Microscopes.}

If you are looking for precision, durability, quality and value in a high performance Stereo Microscope, we invite you to take a closer look at Meiji's RZ Series of Research Stereo Microscopes.

The RZ Series modular system design allows you the freedom to create an ideal instrument for your specific need or application. Featuring a 10:1 zoom ratio, variable double iris diaphragm, and positive detente click stops at 12 positions of magnification. A full range of optional accessories is available, including: Video and photo-micrographic systems, brightfield-darkfield transmitted light stands, ergonomic binocular head, drawing attachment, multiple interchangeable objectives and wide-field eyepieces. Complete system versatility backed by a "Limited Lifetime Warranty."

For more information on these economically priced Stereo Microscopes, please call, FAX, write us or log on to our website today.

\section{MEIJI TECHNO AMERICA}

2186 Bering Drive, San Jose, CA 95131,

Tel: 408.428.9654, FAX: 408.428.0472

Toll Free Telephone: $\mathbf{8 0 0 . 8 3 2 . 0 0 6 0}$ or visit our website at www.meijitechno.com 